\title{
Citrus limonoids interfere with Vibrio harveyi cell- cell signalling and biofilm formation by modulating the response regulator $\mathrm{LuxO}$
}

\author{
Correspondence \\ Bhimanagouda S. Patil \\ b-patil@tamu.edu \\ Suresh D. Pillai \\ spillai@poultry.tamu.edu
}

Received 3 May 2010

Revised 16 September 2010

Accepted 20 September 2010

\author{
Amit Vikram, ${ }^{1}$ Palmy R. Jesudhasan, ${ }^{2}$ G. K. Jayaprakasha, ${ }^{1}$ \\ Suresh D. Pillai ${ }^{1,2}$ and Bhimanagouda S. Patil ${ }^{1}$
${ }^{1}$ Vegetable and Fruit Improvement Center, Department of Horticultural Sciences, Texas A\&M University, College Station, TX 77843, USA
${ }^{2}$ Food Safety and Environmental Microbiology Program, Texas A\&M University, College Station, TX 77843, USA

\begin{abstract}
Citrus limonoids are unique secondary metabolites, characterized by a triterpenoid skeleton with a furan ring. Studies have demonstrated beneficial health properties of limonoids. In addition, certain citrus limonoids play a role in plant defence against insect pests. In the present study, five limonoids were purified from sour orange and evaluated for their ability to inhibit cell-cell signalling. The purified limonoids were tested for their ability to interfere with cell-cell signalling and biofilm formation in Vibrio harveyi. Isolimonic acid, deacetylnomilinic acid glucoside and ichangin demonstrated significant inhibition of autoinducer-mediated cell-cell signalling and biofilm formation. Furthermore, isolimonic acid and ichangin treatment resulted in induced expression of the response regulator gene luxO. In addition, luxR promoter activity was not affected by isolimonic acid or ichangin. Therefore, the ability of isolimonic acid and ichangin to interfere with cell-cell signalling and biofilm formation seems to stem from the modulation of luxO expression. The results suggest that isolimonic acid and ichangin are potent modulators of bacterial cell-cell signalling.
\end{abstract}

\section{INTRODUCTION}

Terpenoids are the largest group of plant secondary metabolites, and are suggested to act in a diverse array of plant physiological processes, including plant defence (Gershenzon \& Dudareva, 2007; Langenheim, 1994). Several triterpenoids such as betulinic acid possess potent antimicrobial activity (Cowan, 1999). A unique class of triterpenoids, termed limonoids, is present in Citrus species. Early research focused on the antifeedant activity of citrus limonoids (Bentley et al., 1990). However, in recent years, these secondary metabolites have been intensively investigated for their potential health benefits. Several reports from our laboratory (Poulose et al., 2005; Tian et al., 2001; Vanamala et al., 2006) and by others (Guthri et al., 2000; Miller et al., 2004; Tanaka et al., 2001)

Abbreviations: $\mathrm{ACN}$, acetonitrile; $\mathrm{Al}-2$, autoinducer-2; $\mathrm{APCl}$, atmospheric pressure chemical ionization; CFS, cell-free culture supernatant; DCM, dichloromethane; EtOAc, ethyl acetate; DNAG, deacetyl nomilinic acid $17 \beta$-D-glucopyranoside; HAl, harveyi autoinducer; IOAG, isoobacunoic acid $17 \beta$-D-glucopyranoside; $\mathrm{MeOH}$, methanol; qRT-PCR, quantitative RT-PCR.

Positive and negative ion mass spectra of citrus limonoids, and fourparameter sigmoidal models for the harveyi autoinducer, autoinducer-2 and $V$. harveyi BB120 biofilm formation, are available with the online version of this paper. suggest a potential role for citrus limonoids in reducing the risks associated with various cancers. Limonoids are postulated to exert their effect by induction of glutathione $S$-transferase enzyme activity (Lam et al., 1989; Perez et al., 2009), apoptosis (Poulose et al., 2005), antioxidant activity (Yu et al., 2005) and suppression of cyclooxygenase 2/ inducible nitric oxide synthase (Vanamala et al., 2006).

Limonoids are distributed throughout the citrus plant, including the leaves, branches and fruit (McIntosh \& Mansell, 1983), suggesting a possible defence function of these secondary metabolites in plants (McIntosh, 2000). Concurrent with this hypothesis, the antifeedant activity of citrus limonoids has been reported in several studies (Champagne et al., 1992; Ruberto et al., 2002). It has been suggested that increasing oxidation and skeletal rearrangement are associated with increased activity against insects. However, structurally simple limonoids present in the family Meliaceae are more potent insect repellents than complex citrus limonoids (Champagne et al., 1992). Furthermore, limonoids isolated from the neem tree (Azadirachta indica, family Meliaceae) also demonstrate antibacterial activity (Atawodi \& Atawodi, 2009). In contrast, reports elucidating the impact of citrus limonoids on micro-organisms are relatively limited. One study demonstrated the impact of limonin and nomilin on 
HIV-1 replication (Battinelli et al., 2003). Furthermore, it has been suggested that citrus limonoids do not inhibit bacterial growth (Champagne et al., 1992).

The elucidation of novel targets for drug development provides an opportunity to screen compounds that otherwise do not possess growth-inhibitory properties. A recently identified target is bacterial cell-cell signalling (also termed quorum sensing). Quorum sensing has been defined as coordinated gene expression in response to cell density (Bassler \& Losick, 2006). Bioluminescence production in Vibrio harveyi is a quorum sensing-controlled process, and the various events in the signalling pathway have been well elucidated. Bioluminescence production in $V$. harveyi is controlled by three coincidence detectors that are part of a typical two-component pathway. The three coincidence detectors, LuxN, LuxPQ and CqsS, converge on the phosphorelay protein LuxU, which in turn activates the response regulator LuxO. LuxO activates the transcription of small antisense RNAs that regulate the production of luminescence by regulating the master regulator LuxR. Cell-cell signalling regulates various pathogenic processes in several bacteria (Erickson et al., 2002; Sircili et al., 2004; Walters \& Sperandio, 2006). It is postulated that interference with bacterial cell-cell signalling attenuates bacterial pathogenicity (Rasmussen \& Givskov, 2006). Consistent with this hypothesis, several synthetic and natural products have been demonstrated to interfere with cell-cell signalling and consequently to affect bacterial pathogenicity (Hentzer et al., 2003; Manefield et al., 2002; Persson et al., 2005; Rasmussen et al., 2005). Furthermore, plant secondary metabolites, such as halogenated furanones (Givskov et al., 1996), polyphenols (Huber et al., 2003) and organosulfur compounds from garlic (Persson et al., 2005), have been reported to interfere with cell-cell signalling.

Grapefruit components, such as furocoumarins, limonoids and flavonoids, have been reported to interfere with cellcell signalling (Girennavar et al., 2008; Vikram et al., 2010a, b). We were also interested in whether certain unique limonoids present in sour orange also possess the ability to interfere with bacterial cell-cell signalling. The present study provides evidence that certain citrus limonoids are potent inhibitors of cell-cell signalling.

\section{METHODS}

Materials. Reagent and HPLC-grade methanol $(\mathrm{MeOH})$, ethyl acetate (EtOAc), acetonitrile (ACN), dichloromethane (DCM), molecular biology-grade DMSO and TLC silica gel 60F-254 plates were purchased from Fisher Scientific. All restriction enzymes and Deep Vent DNA polymerase were purchased from New England Biolabs.

Plant material. Sour orange (Citrus aurantium L.) fruits were collected from the Texas A\&M University Kingsville Citrus Center, Weslaco, TX, USA. Seeds were separated from the fruits and air-dried under shade at $25{ }^{\circ} \mathrm{C}$ for $7-8$ days to obtain $\sim 2 \%$ moisture level and were ground to powder (40-60 mesh size).
Extraction and purification of limonoids. Seed powder $(2.0 \mathrm{~kg})$ was extracted successively for $8 \mathrm{~h}$ each with hexane, EtOAc and $\mathrm{MeOH}$ in a Soxhlet apparatus. The EtOAc and $\mathrm{MeOH}$ extracts were filtered and concentrated under vacuum on a Rotavapor R-200 rotary evaporator (Buchi). The EtOAc extract $(30 \mathrm{~g})$ was dissolved in $500 \mathrm{ml} \mathrm{DCM}$ and extracted with $250 \mathrm{ml}$ water. The vacuum-dried DCM fraction $(28.9 \mathrm{~g})$ was chromatographed on a silica gel column ( $300 \mathrm{~g})$ with a stepwise linear gradient of EtOAc in DCM. Compounds $1 \mathrm{~A}, 1 \mathrm{~B}$ and $1 \mathrm{C}$ were eluted with DCM/EtOAc (92.5:7.5, 85:15 and 80:20, respectively). Yields of compounds $1 \mathrm{~A}, 1 \mathrm{~B}$ and $1 \mathrm{C}$ were 413,805 and $24 \mathrm{mg}$, respectively.

The $\mathrm{MeOH}$ extract was processed according to our previously published method (Jayaprakasha et al., 2006). The first column was packed with Dowex $\mathrm{H}^{+}$resin and the second was packed with Sepabeads adsorbant resin SP 70 (Sigma-Aldrich). The two columns were connected in tandem and vacuum-dried $\mathrm{MeOH}$ extract was loaded on the Dowex resin column. The column was washed thoroughly with deionized water. The wash from the Dowex column was passed over a Sepabeads resin column to adsorb limonoids. The Sepabeads column was later separated from the Dowex column and eluted with a stepwise linear gradient of $\mathrm{ACN}$ in water. Compounds $1 \mathrm{D}$ and $1 \mathrm{E}$ were eluted with $12.5: 87.5$ and 15:85 ACN/water, respectively. Fractions containing compound 1D in higher concentration were pooled and concentrated to yield $1.47 \mathrm{~g}$ of colourless crystalline product. The fractions with higher concentrations of compound $1 \mathrm{E}$ were pooled, dried under vacuum and redissolved in water/ACN $(1: 1)$ to yield $350 \mathrm{mg}$ of colourless compound.

Analysis. All the fractions and purified compounds were analysed by TLC and HPLC. Fractions and purified limonoids were chromatographed on silica gel 60F-254 plates (Fisher Scientific) and detected with Ehrlich's reagent ( $2 \% \mathrm{~N}, \mathrm{~N}$-dimethylaminobenzaldehyde in ethanol), as described previously (Maier \& Grant, 1970; Vikram et al., 2010b).

HPLC was conducted according to a previously published method (Vikram et al., 2007). Briefly, all the column fractions and purified limonoids were filtered through a $0.45 \mu \mathrm{m}$ pore-size filter and chromatographed on a $\mathrm{C}_{18}$ Phenomenex Gemini series column $(5 \mu \mathrm{m}$ particle size, $250 \times 4.6 \mathrm{~mm}$ ). The limonoids were detected at $210 \mathrm{~nm}$ with a Diode Array detector 235C (Perkin Elmer). The gradient mobile phase was $3 \mathrm{mM}$ phosphoric acid and ACN.

Identification of compounds and preparation of stock solution. Identities of the purified compounds were confirmed by atmospheric pressure chemical ionization (APCI)/electrospray ionization MS. The spectra of the purified compounds were compared with published data (Manners et al., 2000). All the limonoids were dissolved in DMSO at a concentration of $20 \mathrm{mg} \mathrm{ml}^{-1}$.

Bacterial strains and media. $V$. harveyi strains $\mathrm{BB} 170$ (luxN::Tn5), BB886 (luxPQ::Tn5), BB120 (wild-type), JAF483 (luxO D47A), JAF553 (luxU H58A), BNL258 (hfq::Tn5lacZ) and JAF548 (luxO D47E, black) were kindly provided by B. L. Bassler (Princeton University, Princeton, NJ, USA) (Freeman \& Bassler, 1999a, b; Lenz et al., 2004; Surette \& Bassler, 1998). Escherichia coli \#5, an environmental isolate (Qin et al., 2004), was used as a positive control for autoinducer-2 (AI-2) activity. Autoinducer bioassay (AB) or Luria Marine (LM) media were used to culture the $V$. harveyi strains (Lu et al., 2004; Surette \& Bassler, 1998).

Plasmids. The molecular biology techniques were used as described by Sambrook \& Russell (2001). The chloramphenicol-resistance $\left(\mathrm{Cml}^{\mathrm{R}}\right)$ gene was amplified from vector pBAD33 and cloned into vector pFZY1 by partial digestion with PstI, and the resultant vector was termed pAV09. Next, the luxR promoter $(+400$ to -56$)$ was cloned into pAV09, resulting in plasmid pAV10. DNA primers for the $\operatorname{luxR}$ promoter were designed with a one-base modification to 
generate EcoR1 and HindIII restriction sites. The fragment was amplified by PCR using Deep Vent DNA polymerase and cloned into plasmid pAV09 ahead of lacZ to generate plasmid pAV10. V. harveyi BB120 was transformed with pAV10 by electroporation at $2100 \mathrm{~V}$ (Sambrook \& Russell, 2001). The transformed colonies were selected and maintained on agar plates supplemented with $\mathrm{Cml}\left(10 \mu \mathrm{g} \mathrm{ml}{ }^{-1}\right)$.

Furthermore, $\operatorname{lu} x U$, $l u x O$ and $h f q$ were amplified with primers carrying restriction sites for KpnI, SalI (luxU), SmaI, PstI (luxO) and SacI, SalI $(h f q)$. The amplified fragments were digested with the respective pairs of restriction enzymes and cloned into pBAD33. The new plasmids were termed pAV05 (luxU), pAV06 ( $h f q)$ and pAV07 (luxO). The plasmids were maintained in E. coli $\mathrm{DH} 10 \mathrm{~B}$ and electroporated into $V$. harveyi JAF553 (luxU), JAF483 (luxO) and BNL258 ( $h f q$ ). The resulting strains were then termed AVS40 (JAF483+pAV07), AVS41 (BNL258 + pAV06) and AVS42 (JAF553 + pAV05).

Growth and metabolic activity. Overnight cultures of $V$. harveyi BB120 were diluted 100-fold in AB media and exposed to limonoids $\left(100 \mu \mathrm{g} \mathrm{ml}^{-1}\right)$ or an equivalent volume of DMSO. The cultures were grown for $16 \mathrm{~h}$ and $\mathrm{OD}_{600}$ was measured every 15 min by using a Synergy HT Multi-Mode Microplate Reader (BioTek Instruments). The instrument was set to maintain a temperature of $30{ }^{\circ} \mathrm{C}$ and plates were constantly shaken at medium speed between readings. The data are presented as the mean of three biological replicates. To verify the results from the optical density experiment independently, the metabolic activity of $V$. harveyi in the presence of limonoids was measured by AlamarBlue (Invitrogen). The metabolic activity of $V$. harveyi was measured in a similar fashion as a growth curve with the addition of $25 \mu$ l AlamarBlue, and $A_{570}$ and $\mathrm{OD}_{600}$ were monitored. The mean percentage reduction of AlamarBlue (Wang et al., 2009) from three biological replicates was calculated and plotted against time.

Bioluminescence assay. The bioluminescence assay was carried out as described previously (Vikram et al., 2010a). In brief, cell-free culture supernatants (CFSs) were prepared from E. coli \#5 and V. harveyi BB120 by culturing in Luria-Bertani (LB) and LM media, respectively, to achieve high concentrations of autoinducer activity, followed by centrifugation at 10000 r.p.m. for $10 \mathrm{~min}$ in a microcentrifuge. The supernatants were collected and filtered through a $0.2 \mu \mathrm{m}$ pore-size membrane filter and stored at $-20{ }^{\circ} \mathrm{C}$. Inhibition of autoinducer [harveyi autoinducer (HAI) and AI-2]-mediated bioluminescence was measured in a 96-well plate assay ( $\mathrm{Lu}$ et al., 2004). The final concentrations of citrus limonoids tested were 6.25, $12.5,25,50$ and $100 \mu \mathrm{g} \mathrm{ml}^{-1}$. Diluted (5000-fold) overnight cultures $(90 \mu \mathrm{l})$ of reporter strains BB886 (for HAI) and BB170 (for AI-2) were incubated with $5 \mu \mathrm{l} \mathrm{CFS,} 0.5 \mu \mathrm{l}$ limonoids or DMSO, and $4.5 \mu \mathrm{l}$ sterile $\mathrm{AB}$ medium at $30{ }^{\circ} \mathrm{C}$ with shaking at 100 r.p.m. Light production was measured by a Victor ${ }^{2} 1420$ multilabel counter (Beckman Coulter) in luminescence mode. The values were recorded as relative light units and used in calculation (Lu et al., 2004).

Overnight cultures of strains JAF553, JAF483, BNL258, AVS40, AVS41 and AVS42 were diluted 5000-fold and treated with isolimonic acid, ichangin or DMSO (control) (all at $100 \mu \mathrm{g} \mathrm{ml}^{-1}$ ). One hundred microlitres of each was placed in a 96-well plate and grown for $4 \mathrm{~h}$ at $30{ }^{\circ} \mathrm{C}$ with shaking at 100 r.p.m. Luminescence was measured as described above. The relative light units from three biological replicates are presented as mean \pm SD. In addition, $\mathrm{OD}_{600}$ values in the presence of DMSO, isolimonic acid and ichangin for strains JAF553 $(0.38 \pm 0.1$, $0.36 \pm 0.1$ and $0.38 \pm 0.07$, respectively), JAF483 $(0.33 \pm 0.07,0.32 \pm 0.03$ and $0.35 \pm 0.02)$, BNL258 $(0.27 \pm 0.11,0.26 \pm 0.04$ and $0.28 \pm 0.03)$, AVS40 $(0.24 \pm 0.05,0.25 \pm 0.02$ and $0.24 \pm 0.18)$, AVS41 $(0.2 \pm 0.08$, $0.21 \pm 0.04$ and $0.2 \pm 0.02)$ and AVS42 $(0.28 \pm 0.07,0.27 \pm 0.13$ and $0.28 \pm 0.05)$ at the time of measurement of luminescence were recorded.
Biofilm assay. The biofilm assay was conducted as described previously (Vikram et al., 2010a). An overnight culture of $V$. harveyi BB120 was diluted 1:50 in LM medium and $190 \mu \mathrm{l}$ of this fresh culture was incubated with $9 \mu \mathrm{l}$ sterile medium and $1 \mu \mathrm{l}$ DMSO or limonoids $\left(6.25,12.5,25,50\right.$ or $\left.100 \mu \mathrm{g} \mathrm{ml}^{-1}\right)$ dissolved in DMSO. $V$. harveyi JAF548 was used as negative control for the assay. The culture was placed in polystyrene 96-well plates (Fischer Scientific) and incubated at $26{ }^{\circ} \mathrm{C}$ for $24 \mathrm{~h}$ without shaking. Total biofilm mass was quantified by washing with phosphate buffer (0.1 M, pH 7.4), followed by staining with $0.3 \%$ crystal violet (Fisher) for $20 \mathrm{~min}$. The dye associated with biofilm was dissolved with $200 \mu 133 \%$ acetic acid, and $A_{570}$ was measured. The mean \pm SD of three biological replicates is presented.

RNA extraction and relative quantification of transcripts. An overnight culture of $V$. harveyi BB120 was diluted 100-fold with fresh $\mathrm{AB}$ medium, treated with isolimonic acid $\left(100 \mu \mathrm{g} \mathrm{ml}^{-1}\right)$, ichangin $\left(100 \mu \mathrm{g} \mathrm{ml}^{-1}\right)$ or an equivalent volume of DMSO, and grown further at $30{ }^{\circ} \mathrm{C}$ with shaking at 200 r.p.m. for 4 h. Bacterial cells were collected by centrifugation at $5000 \mathrm{~g}$ for $10 \mathrm{~min}$. RNA was purified by using the RNeasy Mini Kit (Qiagen) and used as template for cDNA synthesis, as described previously (Vikram et al., 2010a). For quantification of qrr1, RNA was extracted by using TRIzol (Invitrogen) according to the manufacturer's instructions. For quantification, $25 \mathrm{ng}$ cDNA was amplified with $10 \mathrm{pmol}$ of primers and $10 \mu \mathrm{l}$ SYBR Green (Applied Biosystems) for 40 amplification cycles (Vikram et al., 2010a). All measurements were made on three biological replicates. Amplification of target sequences was done on an ABI Prism $7000 \mathrm{HT}$ sequence detection system (Applied Biosystems). Relative quantification of target genes was calculated via the $2^{\Delta \Delta C_{t}}$ method (Livak \& Schmittgen, 2001) and values were expressed as mean fold change $( \pm$ SD). Primers (Table 1) were designed by Primer3 software (Rozen \& Skaletsky, 2000).

$\boldsymbol{\beta}$-Galactosidase assays. An overnight culture of $V$. harveyi $\mathrm{BB} 120$ containing plasmid pAV10 was diluted 100 -fold in AB medium. The diluted culture was treated with isolimonic acid, ichangin (both at $100 \mu \mathrm{g} \mathrm{ml}^{-1}$ ) or an equivalent volume of DMSO, and grown for $4 \mathrm{~h}$ at $30{ }^{\circ} \mathrm{C}$ with shaking at 200 r.p.m. The $\beta$-galactosidase assay was performed as described by Miller (1972).

Statistical analysis. Inhibition of AI activity was calculated from the formula $100-[$ (relative AI activity/relative activity of positive control $) \times 100]($ Lu et al., 2004; Vikram et al., 2010a) and is expressed as a percentage $($ mean $\pm \mathrm{SD})$. The percentage inhibition of biofilm formation was calculated as $100-\left[\left(A_{570}\right.\right.$ of sample well $/ A_{570}$ of positive control $) \times 100$ ] and is expressed as mean \pm SD. Non-linear regression analysis and $t$ tests were conducted with SIGMAPLOT 11.0 (Systat Software).

The effects of different limonoids on each activity were analysed with an analysis of variance (ANOVA) followed by Tukey's pairwise multiple comparison test on SPSS 16.0 (SPSS, Inc.). The effect was considered significant at $P<0.05$. The percentage inhibition and $\log _{10}$ (concentration in $\mu \mathrm{M}$ ) data from acyl homoserine lactone (AHL), AI-2 and biofilm assays were fitted to a four-parameter sigmoid model $y=y_{0}+a /\left\{1+\exp \left[-\left(x-x_{0}\right) / b\right]\right\}$ by using SIGMAPLOT 11.0. The $\mathrm{IC}_{90}$ and $\mathrm{IC}_{50}$ values were calculated from the model.

\section{RESULTS}

\section{Purification and identification of citrus limonoids}

Sour orange seed EtOAc extract yielded three aglycones. The compounds were analysed by HPLC according to Vikram et al. (2007) and found to be $>96 \%$ pure. The 
Table 1. Primers used in the study

\begin{tabular}{|c|c|c|}
\hline Gene & $\begin{array}{l}\text { Forward or } \\
\text { reverse primer }\end{array}$ & Sequence $\left(5^{\prime}-3^{\prime}\right)$ \\
\hline \multicolumn{3}{|l|}{ Real-time PCR } \\
\hline \multirow[t]{2}{*}{$h f q$} & Forward & ATGGCTAAGGGGCAATCTCT \\
\hline & Reverse & ACTGTGGTGGCTCACTGGAC \\
\hline \multirow[t]{2}{*}{$\operatorname{luxO}$} & Forward & GGCACTTTACCGCTCTTACC \\
\hline & Reverse & GTCTGGGTGGCTTTTCTTCA \\
\hline \multirow[t]{2}{*}{$\operatorname{luxP}$} & Forward & GATTTGACCACGCAGAAGG \\
\hline & Reverse & CTTTCGCAGCATCATAGCC \\
\hline \multirow[t]{2}{*}{$\operatorname{lux} Q$} & Forward & CGTTCACTCGGTTGTCTTCC \\
\hline & Reverse & GGGCTTGGTCTTGCGATT \\
\hline \multirow[t]{2}{*}{$\operatorname{luxR}$} & Forward & GTCAATGCCCTCAACCAAGT \\
\hline & Reverse & TCTTCACGCCCAGTTTACG \\
\hline \multirow[t]{2}{*}{$\operatorname{luxS}$} & Forward & AAAAGGAGACACCATCACGG \\
\hline & Reverse & TGCTGCTCTGAAGGCGTT \\
\hline \multirow[t]{2}{*}{$q r r 1$} & Forward & CCCCTCGGGTCACCTATCCAACT \\
\hline & Reverse & GGCAGTCGGATCTATTGGCTCGTTC \\
\hline \multirow[t]{2}{*}{ rpoA } & Forward & CACAGGGCCCGAGCCTGATTT \\
\hline & Reverse & ACCACAGGGCCCGAGCCTG \\
\hline \multicolumn{3}{|l|}{ Cloning } \\
\hline \multirow[t]{2}{*}{$\operatorname{luxR}$} & Forward & CGAAGCCAAACTGCAAGAATTCGTTCTTCTGCA \\
\hline & Reverse & TGTACCGATTGGAACAAGCTTGCGGAACAG \\
\hline \multirow[t]{2}{*}{$\operatorname{lux} U$} & Forward & GCAAAATTCATGGTACCTGACATTATGACGG \\
\hline & Reverse & TTACTGTCTAACTAGTCGACAAGCATTGAG \\
\hline \multirow[t]{2}{*}{$\operatorname{luxO}$} & Forward & ACATCTAATGCCCGGGTGATTATGTCTACGA \\
\hline & Reverse & ATCGCTACCAATTTCTGCAGACAGTTCTTCAA \\
\hline \multirow[t]{2}{*}{$h f q$} & Forward & AGACAGATGTGGGAGCTCTTAGATGGGGA \\
\hline & Reverse & TGTGGGGATTGTCGACTGCCAGTCACAA \\
\hline \multirow[t]{2}{*}{$\mathrm{cml}$} & Forward & ATGCCATAGCATTTTTATCC \\
\hline & Reverse & GATTTAATCTGTATCAGG \\
\hline
\end{tabular}

identities of the purified compounds were confirmed by positive ion APCI-mass spectra for aglycones and negative ion APCI for glucosides. Compounds $1 \mathrm{~A}, 1 \mathrm{~B}$ and $1 \mathrm{C}$ were identified as ichangin $(m / z 489, M+1)$, isoobacunoic acid $(m / z 473, \mathrm{M}+1)$ and isolimonic acid $(m / z 471, \mathrm{M}+1)$ (Fig. 1). The mass spectra of these compounds are presented in Supplementary Fig. S1. The MeOH extract yielded two glucosides, 1D and 1E, which were identified as deacetyl nomilinic acid $17 \beta$-D-glucopyranoside (DNAG) $(\mathrm{m} / z$ 669.3) and isoobacunoic acid $17 \beta$-D-glucopyranoside (IOAG) $(\mathrm{m} / z$ 651.2), respectively (Fig. 1$)$. The negative ion mass spectra of DNAG and IOAG are presented in Supplementary Fig. S2. All the compounds were isolated as crystallized products.

\section{Effect of citrus limonoids on cell growth and viability}

Cell growth was measured by monitoring $\mathrm{OD}_{600}$ for $16 \mathrm{~h}$. Limonoids did not affect growth of $V$. harveyi at $100 \mu \mathrm{g} \mathrm{ml}^{-1}$ (Fig. 2a). To validate the findings further, the cell viability of $V$. harveyi in the presence of $100 \mu \mathrm{g}$ limonoids $\mathrm{ml}^{-1}$ was monitored for $16 \mathrm{~h}$ by using AlamarBlue. The results indicated no effect on cell metabolic activity by limonoids (Fig. 2b).

\section{Inhibition of HAl- and Al-2-mediated bioluminescence by citrus limonoids}

Bioluminescence produced by $V$. harveyi mutant strains was utilized as readout for HAI- and AI-2-mediated cellcell signalling. All the tested compounds inhibited HAIand AI-2-mediated bioluminescence in a concentrationdependent manner (Fig. 3). Three of the five tested limonoids, namely isolimonic acid, ichangin and DNAG, demonstrated $>90 \%$ inhibition of AI-2 activity at $100 \mu \mathrm{g} \mathrm{ml}^{-1}$, and therefore $\mathrm{IC}_{90}$ values for AI-2 inhibitory activity were compared. In contrast, $\mathrm{IC}_{50}$ values were compared for HAI activity. Isolimonic acid was the most potent inhibitor of HAI and AI-2 activity (Fig. $3 \mathrm{~b}$ and Supplementary Fig. S3) among the tested limonoids and inhibited $99.23 \%$ of AI-2-mediated bioluminescence at $100 \mu \mathrm{g} \mathrm{ml}^{-1}$ (Fig. 3b). $\mathrm{IC}_{90}$ values for isolimonic acid, DNAG and ichangin for AI-2 activity were 38.90, 123.03 and $194.98 \mu \mathrm{M}$, respectively (Supplementary Fig. S3b). $\mathrm{IC}_{50}$ values for isolimonic acid, DNAG and ichangin against HAI activity were 148.59, 197.70 and $79.43 \mu \mathrm{M}$, respectively (Supplementary Fig. S3a). Isoobacunoic acid (Fig. $3 \mathrm{c}$ ) had the lowest $\mathrm{IC}_{50}$ value of $65.01 \mu \mathrm{M}$ against HAI activity; however, the four-parameter sigmoid plot demonstrated that the activity of isoobacunoic acid was saturated 


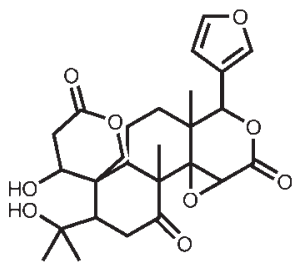

Ichangin (A)<smiles>CC1(C)OC(CC(=O)O)C2(C)C1CCC1(C)C2CCC2(C)C(c3ccoc3)OC(=O)C3OC321</smiles>

Isoobacunoic acid (B)<smiles>CC1(C)OCC2(C(O)CC(=O)O)C3CCC4(C)C(c5ccoc5)OC(=O)C5OC54C34C(=O)CC1C24C</smiles>

Isolimonic acid (C)

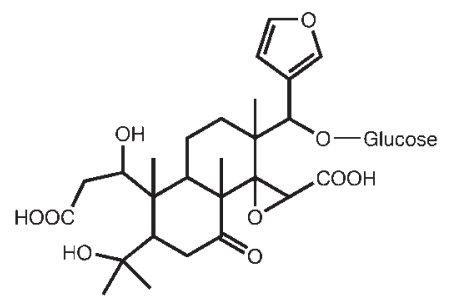

DNAG (D)<smiles>COC(c1ccoc1)C1(C)CCC2C(CC(=O)O)OC(=O)CC3C2(C)C2(OC2C(=O)O)C31C</smiles>

IOAG $(E)$

Fig. 1. Structures of the limonoids purified from sour orange in this study.

at $\geqslant 100 \mu \mathrm{M}$ (Supplementary Fig. S3a). Ichangin (Fig. 3a) showed a more linear effect on HAI inhibition, and inhibited AI-2 activity by 9.63-91.58\% (Fig. 3a).

\section{Inhibition of $\boldsymbol{V}$. harveyi biofilm formation}

Isolimonic acid was the most effective inhibitor of $V$. harveyi biofilm formation (Fig. 4 and Supplementary Fig. S4) with an $\mathrm{IC}_{50}$ value of $94.18 \mu \mathrm{M}$. $\mathrm{IC}_{50}$ values for ichangin, isoobacunoic acid, DNAG and IOAG could not be calculated, as these limonoids demonstrated $\leqslant 50 \%$ biofilm inhibition under the experimental conditions. In comparison, the quorum-sensing-negative strain JAF548 showed very low levels of biofilm formation. Ichangin, isoobacunoic acid and DNAG demonstrated similar levels of inhibition on $V$. harveyi BB120 biofilm formation, whereas IOAG was the least effective in inhibiting $V$. harveyi biofilm formation (Fig. 4 and Supplementary Fig. S4).

\section{Effect of limonoids on constitutively luminescent V. harveyi mutants}

Because all the tested limonoids demonstrated inhibitory activity in HAI and AI-2 under the experimental conditions, it is possible that these limonoids are non-specific inhibitors of cell-cell signalling. To test this hypothesis, the effects of the limonoids were investigated in the constitutively bioluminescent mutants JAF553, JAF483 and BNL258 (Freeman \& Bassler, 1999a, b). Based on their potency in bioluminescence assays and structural characteristics, isolimonic acid and ichangin were selected for further study. Strains JAF553 and JAF483 carry point mutations in the luxU and luxO genes, rendering them defective in phosphorelay (Freeman \& Bassler, 1999a, b), while BNL258 contains a Tn5 insertion in the $h f q$ gene, leading to a non-functional Hfq protein (Lenz et al., 2004). We reasoned that a diminished luminescence in these strains would indicate interference with signal transduction downstream of the non-functional gene. Interestingly, isolimonic acid treatment enhanced luminescence production in LuxU (a)

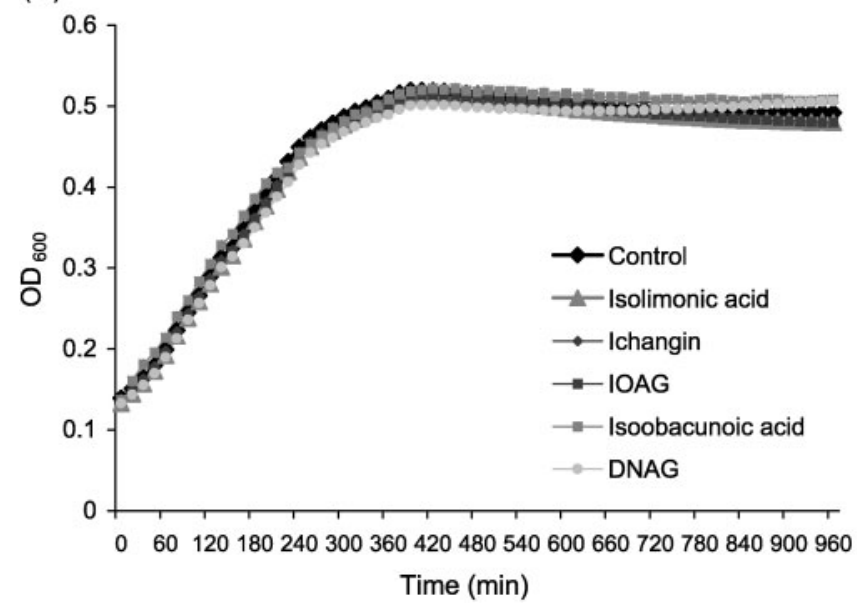

(b)

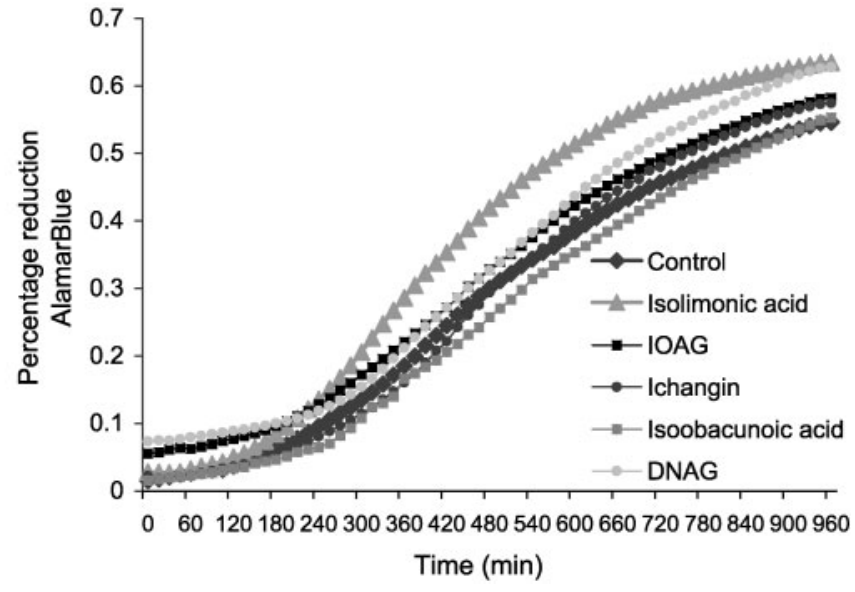

Fig. 2. (a) Growth curve of $V$. harveyi in the presence of limonoids $\left(100 \mu \mathrm{g} \mathrm{ml}^{-1}\right)$. (b) Impact of limonoids on the metabolic activity of $V$. harveyi as measured by AlamarBlue reduction. DNAG, deacetyl nomilinic acid 17 $\beta$-D-glucopyranoside; IOAG, isoobacunoic acid $17 \beta$-D-glucopyranoside. 


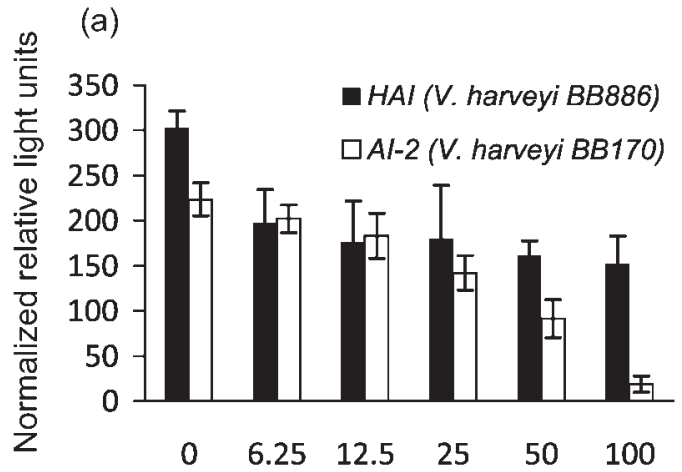

(b)

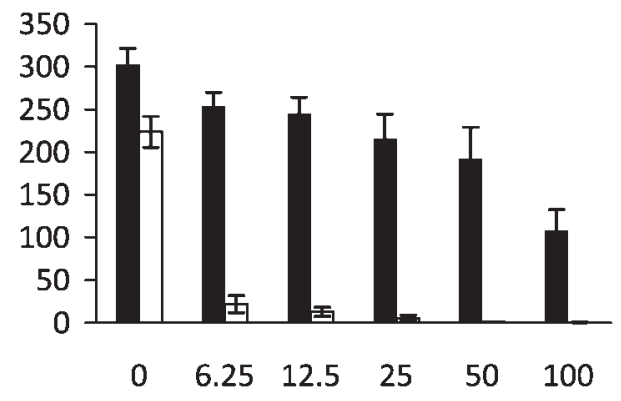

(c)

(d)

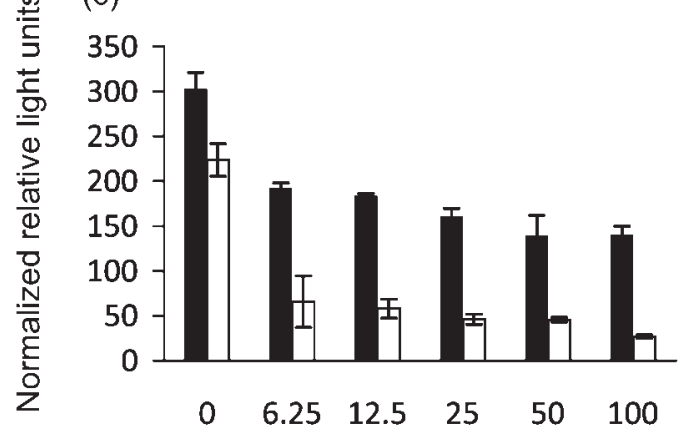

(e)
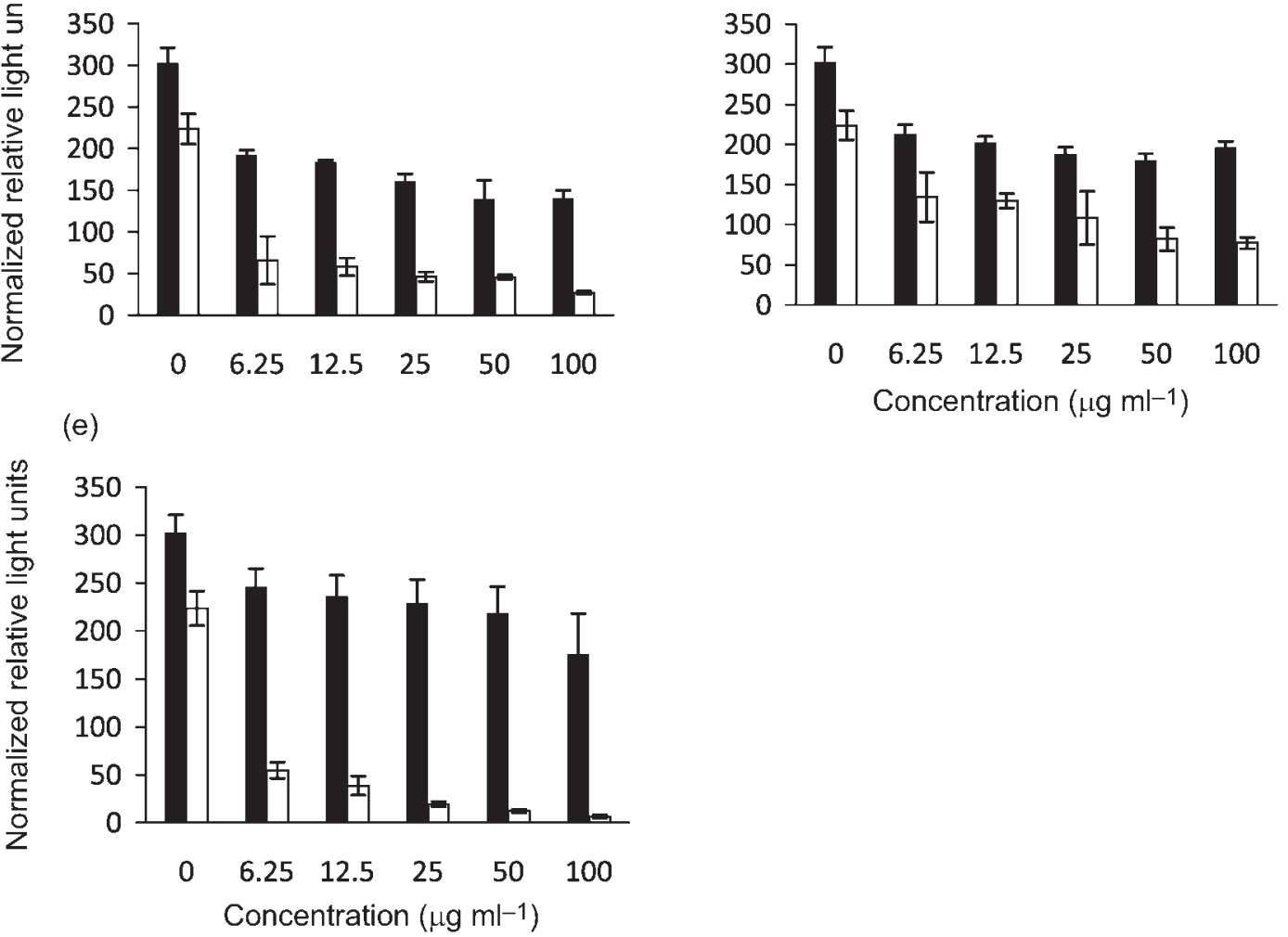

Fig. 3. HAl-1- and Al-2-induced bioluminescence in V. harveyi BB886 and BB170, respectively, in the presence of (a) ichangin, (b) isolimonic acid, (c) isoobacunoic acid, (d) IOAG and (e) DNAG. The relative light units for each strain were normalized by dividing by the value for the negative control (see text). The data are presented as normalized relative light units $($ mean $\pm S D)$.

(6.46\%) and LuxO (64.63\%) mutants significantly, but did not affect luminescence production in the $h f q$ mutant (Fig. 5). Similarly, ichangin treatment induced bioluminescence in strain JAF483 (17.64\%), but reduced the luminescence in LuxU and $h f q$ mutants (Fig. 5). Furthermore, to determine whether the increased luminescence can be negated by expression of a functional copy of the mutant or disrupted gene, luxO, luxU and $h f q$ were expressed in trans under the control of an arabinose promoter. Expression from the plasmid resulted in decreased levels of luminescence in the transformed strains. Bioluminescence levels for isolimonic acid- or ichangin-treated strains were not significantly different from those of the control. The results suggest that isolimonic acid and ichangin are likely to affect the signal transduction pathway at or downstream of LuxO but upstream of Hfq (Fig. 5).

\section{Expression analysis of the signal transduction pathway}

To further understand the enhanced bioluminescence observed in $l u x O$ and $l u x U$ mutants by isolimonic acid 


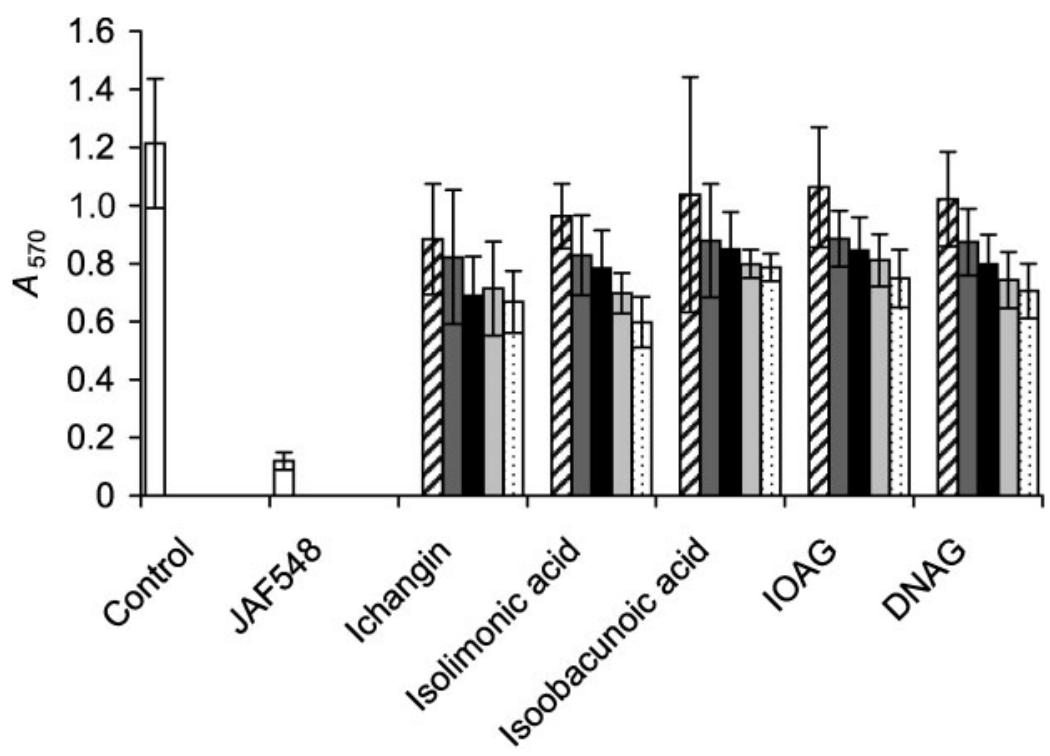

Fig. 4. Inhibitory activity of limonoids against $V$. harveyi BB120 biofilm. The $V$. harveyi biofilm was measured in the presence of limonoids at 6.25 (hatched bars), 12.5 (grey bars), 25 (black bars), 50 (light-grey bars) and $100 \mathrm{~g} \mathrm{ml}^{-1}$ (stippled bars). The data are presented as mean \pm SD.

and ichangin, expression of $\operatorname{lu} x P, \operatorname{lu} x \mathrm{Q}, \operatorname{lu} x O, h f q, \operatorname{lu} x R$ and luxS was investigated in $V$. harveyi $\mathrm{BB} 120$ by using quantitative RT-PCR (qRT-PCR). Isolimonic acid treatment induced expression of $l u x O$ by 3.68 -fold after $4 \mathrm{~h}$ (Fig. 6a). In addition, $h f q$, $l u x P$ and $l u x Q$ (2.53-, 2.42- and 5.29-fold, respectively) were also induced by isolimonic acid treatment. In contrast, $\operatorname{luxR}(-4.44$-fold) was suppressed, while luxS (1.27-fold) was not affected by isolimonic acid. In the presence of ichangin, expression of $\operatorname{lu} x O, \operatorname{lu} x P, \operatorname{lu} x Q$ and $h f q$ was induced 23.7-, 3.54-, 2.64- and 2.53-fold (Fig. 6b), respectively. In addition, ichangin treatment resulted in a 2.4-fold suppression of luxR.

In wild-type $V$. harveyi strains, LuxO regulates levels of $l u x R$ mRNA by activating the transcription of sRNA ( qrr1-5) (Lilley \& Bassler, 2000; Tu \& Bassler, 2007). Isolimonic acid and ichangin appeared to induce $l u x O$ but at the same time suppressed $\operatorname{luxR}$. To confirm further that isolimonic acid and ichangin act by upregulating $\operatorname{lu} x O$, luxR promoter activity was measured. Isolimonic acid (Fig. 6c) and ichangin (Fig. 6d) treatment did not affect $\beta$-galactosidase activity. The empty vector was used as a control and did not demonstrate appreciable $\beta$-galactosidase activity. In addition, qrr1 mRNA levels were quantified by using relative qRT-PCR. The qrr1 gene was induced 8.7- and 12.3-fold by isolimonic acid and ichangin, respectively (Fig. 6e). These results further suggest that isolimonic acid and ichangin influence the cell-cell signalling pathway by modulating luxO expression.

\section{DISCUSSION}

In the present study, three limonoid aglycones and two limonoid glucosides were purified from sour orange seeds.

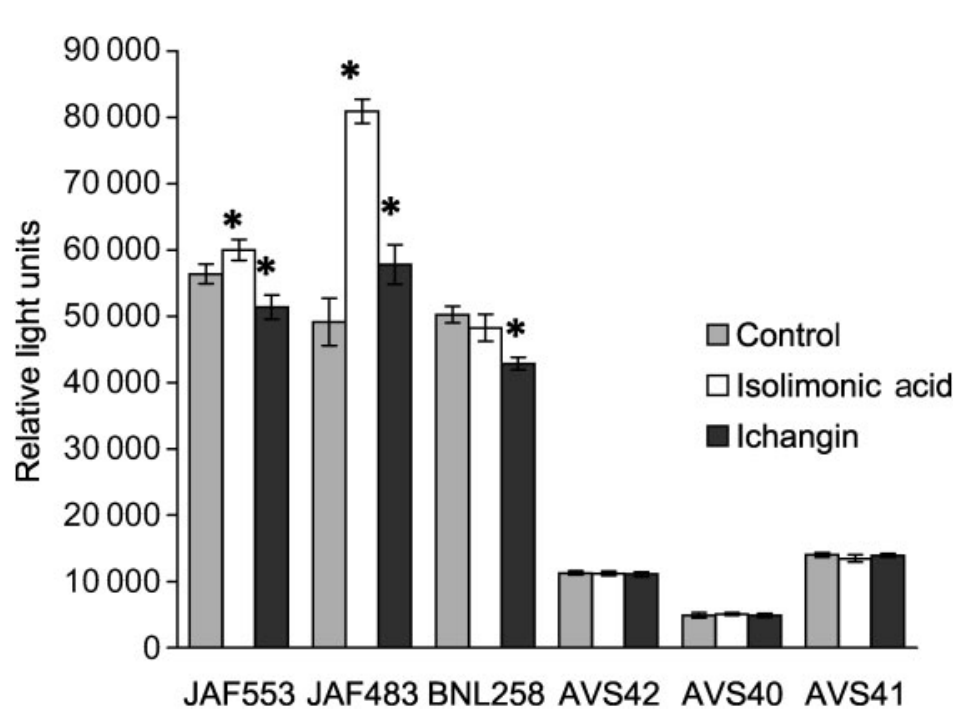

Fig. 5. Impact of isolimonic acid and ichangin $\left(100 \mu \mathrm{g} \mathrm{ml}^{-1}\right)$ on bioluminescence of $V$. harveyi mutants JAF553 (luxU H58A), JAF483 (luxO D47A), BNL258 (hfq::Tn5/acZ), AVS40 (JAF483 complemented with luxO), AVS41 (BNL258 complemented with $h f q$ ) and AVS42 (JAF553 complemented with luxU). 
(a)

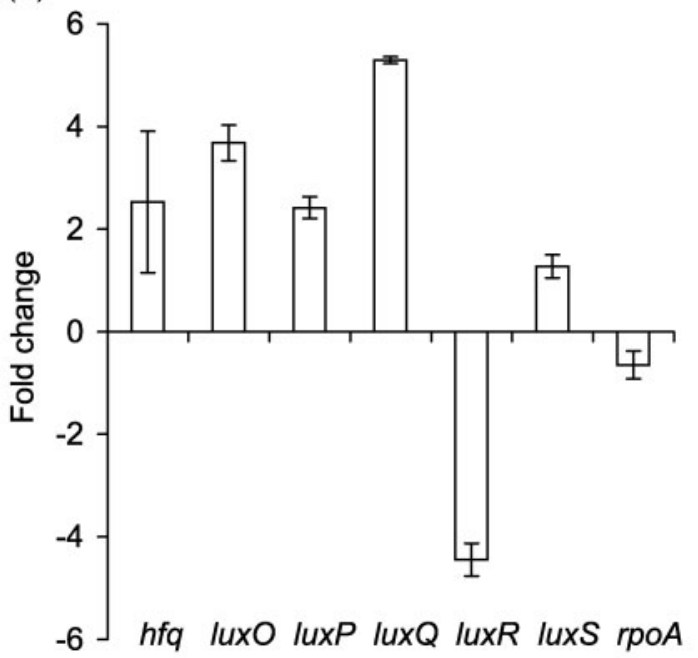

(c)

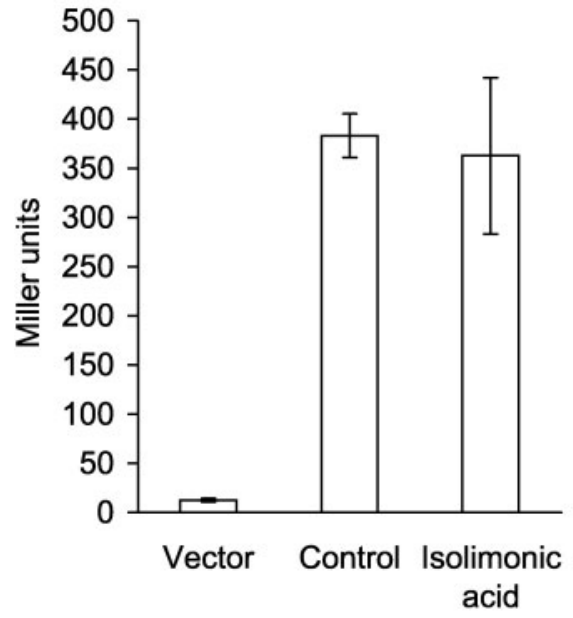

(b)

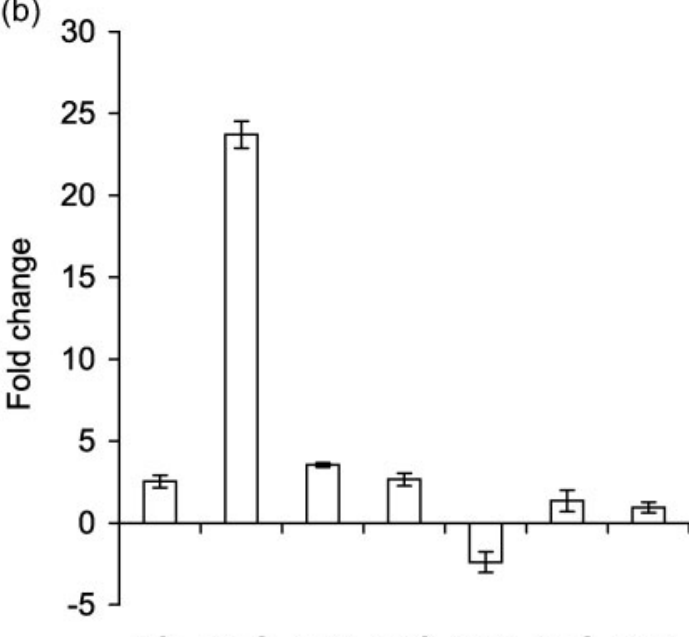

hfq luxO IuxP luxQ luxR luxS rpoA

(e)

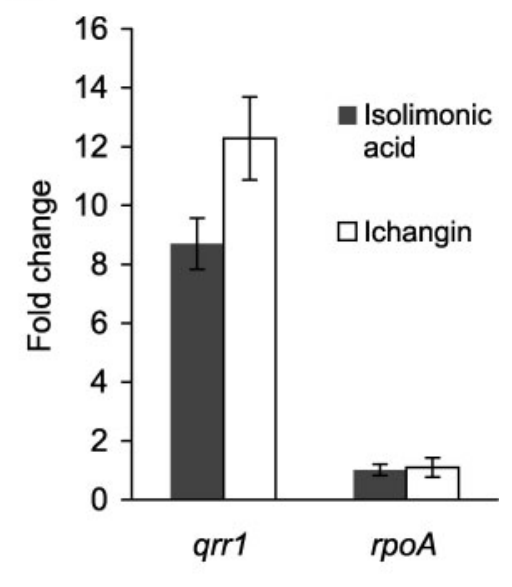

Fig. 6. Expression of the signal transduction pathway and Al-2 synthase in $V$. harveyi strain BB120 upon exposure (at $100 \mu \mathrm{g} \mathrm{ml}^{-1}$ ) to (a) isolimonic acid and (b) ichangin, as measured by qRT-PCR. (c, d) LuxR promoter activity measured in $V$. harveyi BB120 in the presence of (c) isolimonic acid and (d) ichangin. (e) Relative quantification of qrr1 in V. harveyi BB120, upon exposure to isolimonic acid and ichangin (at $100 \mu \mathrm{g} \mathrm{ml}^{-1}$ ).

Despite their higher concentration in citrus juice, limonoid glucosides are difficult to purify owing to their very similar polarities. In addition, flavonoid glycosides, which are present at higher concentrations, interfere with the purification of limonoids. In the current study, we employed a cation $\mathrm{H}^{+}$exchange column. Flavonoid glycosides show weak ionization (Havsteen, 2002) and they are absorbed on the cation exchange column (Dowex), whereas limonoids are adsorbed on the Sepabeads column. The limonoid glucosides were eluted by using water and ACN to obtain DNAG and IOAG as crystallized products.

Bioluminescence production in $V$. harveyi is regulated by a two-component signal transduction pathway via three coincidence detectors (Henke \& Bassler, 2004). The three coincidence detectors, LuxN, LuxPQ and CqsS, converge on the phosphorelay protein $\mathrm{LuxU}$ and share the rest of the pathway (Henke \& Bassler, 2004). To measure HAI and AI-2 inhibitory activity, limonoids were tested in two $V$. harveyi strains carrying mutations in receptors. Strain BB886 is defective in cell signalling mediated by AI-2, whereas strain BB170 (LuxN : : Tn5) does not detect $N$-hydroxybutanoyl-Lhomoserine lactone (Bassler et al., 1997). E. coli \#5 does not produce acylhomoserine lactone (corresponding to HAI), but produces AI-2. Addition of CFS from E. coli \#5 in the AI-2 activity bioassay ensured that the measured activity was due to the presence of AI-2. Furthermore, the reporter strains BB886 and BB170 produce and sense their own autoinducers. Therefore, the time to measure AI activity was chosen carefully. The assay was carried out until the negative control showed a luminescence reading of 100 , which was taken as a final value and analysed. 
Limonoids demonstrated a dose-dependent inhibition of HAI and AI-2 activity. To rule out that the observed effect was due to inhibition of bacterial growth, cell density $\left(\mathrm{OD}_{600}\right)$ in the presence of limonoids was measured. Citrus limonoids did not show growth-inhibitory effects on $V$. harveyi (Fig. 2), consistent with the study of Champagne et al. (1992). Furthermore, suppression of luminescence production suggests that limonoids act by a mechanism that mimics the phosphorylated LuxO or low-density phenotype. The LuxO mutant, locked in the phosphorylated condition, has been further shown to be defective in biofilm formation, indicating positive regulation of biofilm formation in $V$. harveyi by quorum sensing (Anetzberger et al., 2009). Therefore, the biofilm formed by wild-type strain $V$. harveyi $\mathrm{BB} 120$ in the presence of various concentrations of limonoids was measured. Consistent with our hypothesis, a dose-dependent inhibition of biofilm formation was observed. In addition, isolimonic acid, which was the most potent inhibitor in the autoinducer assay, demonstrated significant inhibition of biofilm formation under the experimental conditions. This indicates that the tested limonoids inhibit biofilm formation, possibly by interfering with cell-cell signalling.

Isolimonic acid and ichangin were chosen for further investigation. Both demonstrated significant inhibition of HAI/AI-2 activity and biofilm formation. In addition, ichangin is structurally different from the other tested limonoids (Fig. 1a). We were interested to see whether isolimonic acid and ichangin differed in their mode of action. To determine the probable site of action, the effect of limonoids on constitutively luminescent $V$. harveyi mutants was investigated. Both isolimonic acid and ichangin enhanced luminescence production in the luxO mutant JAF483. The luxO gene in strain JAF483 contains a point mutation and is incapable of phosphorelay, and hence did not activate the transcription of sRNA (Freeman \& Bassler, 1999b). Furthermore, isolimonic acid did not influence luminescence production in the $h f q$ mutant BNL258. In contrast, ichangin treatment caused a small but significant reduction of luminescence in BNL258. The Hfa protein is non-functional in strain BNL258, and consequently luxR mRNA is stable and produces luminescence (Lenz et al., 2004). Taken together, the data indicate that the possible site of action of isolimonic acid is between LuxO and Hfq, whereas ichangin seems to act at LuxO. To gain further insight, luxO mRNA transcript levels were measured by qRT-PCR (Fig. 6a, b). Induction of luxO suggested that isolimonic acid and ichangin modulate the signal transduction pathway by affecting luxO expression. Because LuxO regulates the stability of the luxR mRNA, higher expression of $\operatorname{luxO}$ will result in lower transcript levels of $\operatorname{luxR}$. In addition, induction of $h f q$ by isolimonic acid treatment was also observed. In wild-type $V$. harveyi, $\operatorname{luxO}$ in conjunction with the alternative sigma factor $\sigma^{54}$ regulates the expression of the sRNAs qrr1, qrr2, qrr3, qrr4 and qrr5 (Lilley \& Bassler, 2000; Tu \& Bassler, 2007). In turn, these sRNAs, with the help of Hfq, destabilize the luxR mRNA (Lenz et al., 2004). Consistent with these observations, an induction of qrr1 and suppression of luxR mRNA transcript was observed in $V$. harveyi BB120 in the presence of isolimonic acid and ichangin. Together, higher expression levels of $l u x O$ and $h f q$ plausibly explain the enhanced luminescence observed in $\operatorname{luxO}$ (JAF483) and luxU (JAF553) mutants. Furthermore, the induced expression of $l u x P Q$ may be a response to the induction of $l u x O$. In addition, the results indicate that isolimonic acid did not
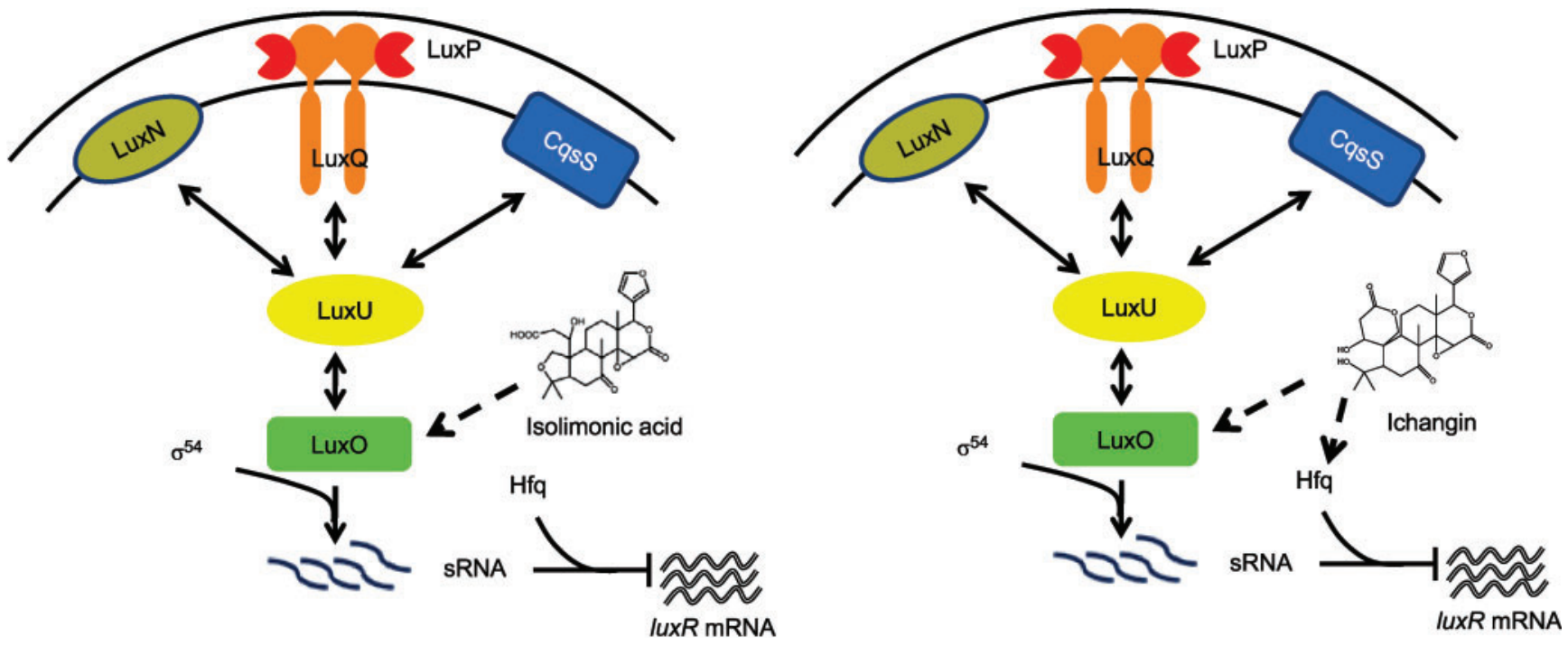

Fig. 7. Speculative model of the effect of isolimonic acid and ichangin on the signal transduction pathway in $V$. harveyi. The broken lines represent unknown modes of action on the expression of luxO. Figure adapted from Henke \& Bassler (2004) and modified to depict the effect of the compounds. 
affect AI-2 production, as luxS expression was unaltered under these experimental conditions. Interestingly, ichangin treatment also produced an expression profile similar to that of isolimonic acid, indicating a closely related mode of action. Like isolimonic acid, ichangin also seems to exert its action primarily by inducing $l u x O$ and $h f q$ (Fig. 6b).

The quantitative PCR results suggest that isolimonic acid and ichangin treatment resulted in decreased $\operatorname{luxR}$ transcript levels. It is possible that the observed reduction in $\operatorname{luxR}$ transcripts is due to decreased transcriptional activity of $\operatorname{luxR}$ and not due to induced expression of $\operatorname{luxO}$. To understand this further, we constructed a plasmid carrying the $l u x R$ promoter fused with $l a c Z$, and measured $\beta$-galactosidase activity in the presence of isolimonic acid and ichangin. The results demonstrated that isolimonic acid and ichangin treatment did not affect $l u x R$ promoter activity. This observation suggests that the decreased level of luxR mRNA transcript level is due to induced expression of luxO. Together, the results suggest that isolimonic acid and ichangin interfere with $V$. harveyi cell-cell signalling by modulating luxO expression (Fig. 7). However, at this point it is not known whether this effect is direct or indirect. Furthermore, a negative feedback loop mechanism is suggested to regulate the levels of the transcriptional regulator HapR in Vibrio cholerae and to aid in switching from a high to a low cell density state (Svenningsen et al., 2008). However, isolimonic acid and ichangin were only tested for their inhibitory effect under low-density conditions. Furthermore, the proposed mechanism (Fig. 7) seems to operate under low-density conditions. It is possible that isolimonic acid and ichangin have different effects at the transition phase from high to low cell density. During the early growth phase, LuxT has been suggested to regulate levels of $l u x O$ (Lin et al., 2000), and it is possible that isolimonic acid and ichangin affect cell-cell signalling by affecting LuxT.

In conclusion, citrus limonoids, specifically isolimonic acid and ichangin, exhibited a strong inhibitory activity against bacterial cell-cell signalling as measured via the $V$. harveyi reporter strain model system. Furthermore, inhibition of quorum sensing-regulated processes, such as biofilm formation, was observed. Finally, isolimonic acid and ichangin appear to exert their effect by modulating the expression of the response regulator luxO and the RNA chaperone $h f q$. However, whether isolimonic acid and ichangin exert direct or indirect effects remains to be elucidated. The current study provides evidence that certain citrus limonoids possess the ability to interfere with bacterial cell-cell signalling in the model organism $V$. harveyi. However, the anti-quorum-sensing activity of citrus limonoids remains to be elucidated for human pathogens.

\section{ACKNOWLEDGEMENTS}

This project was based on work supported by the United States Department of Agriculture Cooperative State Research, Education, and Extension Service Initiative for Future Agricultural and Food Systems (USDA CSREES IFAFS) \#2009-34402-19831 'Designing Foods for Health' through the Vegetable \& Fruit Improvement Center.

\section{REFERENCES}

Anetzberger, C., Pirch, T. \& Jung, K. (2009). Heterogeneity in quorum sensing-regulated bioluminescence of Vibrio harveyi. Mol Microbiol 73, 267-277.

Atawodi, S. \& Atawodi, J. (2009). Azadirachta indica (neem): a plant of multiple biological and pharmacological activities. Phytochem Rev 8, 601-620.

Bassler, B. L. \& Losick, R. (2006). Bacterially speaking. Cell 125, 237246.

Bassler, B. L., Greenberg, E. P. \& Stevens, A. M. (1997). Crossspecies induction of luminescence in the quorum-sensing bacterium Vibrio harveyi. J Bacteriol 179, 4043-4045.

Battinelli, L., Mengoni, F., Lichtner, M., Mazzanti, G., Saija, A., Mastroianni, C. M. \& Vullo, V. (2003). Effect of limonin and nomilin on HIV-1 replication on infected human mononuclear cells. Planta Med 69, 910-913.

Bentley, M. D., Rajab, M. S., Mendel, M. J. \& Alford, A. R. (1990). Limonoid model insect antifeedants. J Agric Food Chem 38, 14001403.

Champagne, D. E., Koul, O., Isman, M. B., Scudder, G. G. E. \& Neil Towers, G. H. (1992). Biological activity of limonoids from the rutales. Phytochemistry 31, 377-394.

Cowan, M. M. (1999). Plant products as antimicrobial agents. Clin Microbiol Rev 12, 564-582.

Erickson, D. L., Endersby, R., Kirkham, A., Stuber, K., Vollman, D. D., Rabin, H. R., Mitchell, I. \& Storey, D. G. (2002). Pseudomonas aeruginosa quorum-sensing systems may control virulence factor expression in the lungs of patients with cystic fibrosis. Infect Immun 70, 1783-1790.

Freeman, J. A. \& Bassler, B. L. (1999a). Sequence and function of LuxU: a two-component phosphorelay protein that regulates quorum sensing in Vibrio harveyi. J Bacteriol 181, 899-906.

Freeman, J. A. \& Bassler, B. L. (1999b). A genetic analysis of the function of LuxO, a two-component response regulator involved in quorum sensing in Vibrio harveyi. Mol Microbiol 31, 665-677.

Gershenzon, J. \& Dudareva, N. (2007). The function of terpene natural products in the natural world. Nat Chem Biol 3, 408-414.

Girennavar, B., Cepeda, M. L., Soni, K. A., Vikram, A., Jesudhasan, P., Jayaprakasha, G. K., Pillai, S. D. \& Patil, B. S. (2008). Grapefruit juice and its furocoumarins inhibits autoinducer signaling and biofilm formation in bacteria. Int J Food Microbiol 125, 204-208.

Givskov, M., de Nys, R., Manefield, M., Gram, L., Maximilien, R., Eberl, L., Molin, S., Steinberg, P. \& Kjelleberg, S. (1996). Eukaryotic interference with homoserine lactone-mediated prokaryotic signalling. J Bacteriol 178, 6618-6622.

Guthri, N., Morley, K., Hasegawa, S., Manner Gary, D. \& Vandenberg, T. (2000). Inhibition of human breast cancer cells by citrus limonoids. In Citrus Limonoids, pp. 164-174. Washington, DC: American Chemical Society.

Havsteen, B. H. (2002). The biochemistry and medical significance of the flavonoids. Pharmacol Ther 96, 67-202.

Henke, J. M. \& Bassler, B. L. (2004). Three parallel quorum-sensing systems regulate gene expression in Vibrio harveyi. J Bacteriol 186, 6902-6914. 
Hentzer, M., Wu, H., Andersen, J. B., Riedel, K., Rasmussen, T. B., Bagge, N., Kumar, N., Schembri, M. A., Song, Z. \& other authors (2003). Attenuation of Pseudomonas aeruginosa virulence by quorum sensing inhibitors. EMBO J 22, 3803-3815.

Huber, B., Eberl, L., Feucht, W. \& Polster, J. (2003). Influence of polyphenols on bacterial biofilm formation and quorum-sensing. $Z$ Naturforsch C 58, 879-884.

Jayaprakasha, G. K., Patil, B. S. \& Bhat, N. G. (2006). A process for isolation of limonin glucoside and isoobacunoic acid glucoside from citrus seeds. USA patent application no. 60/74437.

Lam, L. K. T., Li, Y. \& Hasegawa, S. (1989). Effects of citrus limonoids on glutathione $S$-transferase activity in mice. J Agric Food Chem 37, 878-880.

Langenheim, J. H. (1994). Higher plant terpenoids: a phytocentric overview of their ecological roles. J Chem Ecol 20, 1223-1280.

Lenz, D. H., Mok, K. C., Lilley, B. N., Kulkarni, R. V., Wingreen, N. S. \& Bassler, B. L. (2004). The small RNA chaperone Hfq and multiple small RNAs control quorum sensing in Vibrio harveyi and Vibrio cholerae. Cell 118, 69-82.

Lilley, B. N. \& Bassler, B. L. (2000). Regulation of quorum sensing in Vibrio harveyi by LuxO and Sigma-54. Mol Microbiol 36, 940-954.

Lin, Y. H., Miyamoto, C. \& Meighen, E. A. (2000). Cloning and functional studies of a luxO regulator LuxT from Vibrio harveyi. Biochim Biophys Acta 1494, 226-235.

Livak, K. J. \& Schmittgen, T. D. (2001). Analysis of relative gene expression data using real-time quantitative PCR and the $2^{\Delta \Delta C}$ method. Methods 25, 402-408.

Lu, L., Hume, M. E. \& Pillai, S. D. (2004). Autoinducer-2 like activity associated with foods and its interaction with food additives. J Food Prot 67, 1457-1462.

Maier, V. P. \& Grant, E. R. (1970). Specific thin-layer chromatography assay of limonin, a citrus bitter principle. J Agric Food Chem 18, 250 252.

Manefield, M., Rasmussen, T. B., Henzter, M., Andersen, J. B., Steinberg, P., Kjelleberg, S. \& Givskov, M. (2002). Halogenated furanones inhibit quorum sensing through accelerated LuxR turnover. Microbiology 148, 1119-1127.

Manners, G. D., Hasegawa, S., Barnett, R. D. \& Wong, R. Y. (2000). LCMS and NMR techniques for the analysis and characterization of Citrus limonoids. In Citrus Limonoids: Functional Chemicals in Agriculture and Foods, pp. 40-59. Edited by M. A. Berhow, S. Hasegawa \& G. D. Manners. Washington, DC: American Chemical Society.

McIntosh, C. A. (2000). Quantification of limonin and limonoate Aring monolactone during growth and development of citrus fruit and vegetative tissues by radioimmunoassay. In Citrus Limonoids: Functional Chemicals in Agriculture and Foods, pp. 73-95. Edited by M. A. Berhow, S. Hasegawa \& G. D. Manners. Washington, DC: American Chemical Society.

Mclntosh, C. A. \& Mansell, R. L. (1983). Distribution of limonin during the growth and development of leaves and branches of Citrus paradisi. J Agric Food Chem 31, 319-325.

Miller, J. H. (1972). Assay for $\beta$-galactosidase. In Experiments in Molecular Genetics, pp. 352-355. Cold Spring Harbor, NY: Cold Spring Harbor Laboratory.

Miller, E. G., Porter, J. L., Binnie, W. H., Guo, I. Y. \& Hasegawa, S. (2004). Further studies on the anticancer activity of citrus limonoids. J Agric Food Chem 52, 4908-4912.

Perez, J. L., Jayaprakasha, G. K., Valdivia, V., Munoz, D., Dandekar, D. V., Ahmad, H. \& Patil, B. S. (2009). Limonin methoxylation influences the induction of glutathione $S$-transferase and quinone reductase. J Agric Food Chem 57, 5279-5286.
Persson, T., Hansen, T. H., Rasmussen, T. B., Skinderso, M. E., Givskov, M. \& Nielsen, J. (2005). Rational design and synthesis of new quorum-sensing inhibitors derived from acylated homoserine lactones and natural products from garlic. Org Biomol Chem 3, 253262.

Poulose, S. M., Harris, E. D. \& Patil, B. S. (2005). Citrus limonoids induce apoptosis in human neuroblastoma cells and have radical scavenging activity. $J$ Nutr 135, 870-877.

Qin, Y., Luo, Z.-Q. \& Farrand, S. K. (2004). Domains formed within the N-terminal region of the quorum-sensing activator TraR are required for transcriptional activation and direct interaction with RpoA from Agrobacterium. J Biol Chem 279, 40844-40851.

Rasmussen, T. B. \& Givskov, M. (2006). Quorum sensing inhibitors: a bargain of effects. Microbiology 152, 895-904.

Rasmussen, T. B., Skindersoe, M. E., Bjarnsholt, T., Phipps, R. K., Christensen, K. B., Jensen, P. O., Andersen, J. B., Koch, B., Larsen, T. O. \& other authors (2005). Identity and effects of quorum-sensing inhibitors produced by Penicillium species. Microbiology 151, 13251340.

Rozen, S. \& Skaletsky, H. J. (2000). Primer3 on the WWW for general users and for biologist programmers. In Bioinformatics Methods and Protocols: Methods in Molecular Biology, pp. 365-386. Edited by S. Krawetz \& S. Misener. Totowa, NJ: Humana Press.

Ruberto, G., Renda, A., Tringali, C., Napoli, E. M. \& Simmonds, M. S. J. (2002). Citrus limonoids and their semisynthetic derivatives as antifeedant agents against Spodoptera frugiperda larvae. A structureactivity relationship study. J Agric Food Chem 50, 6766-6774.

Sambrook, J. \& Russell, D. W. (2001). Molecular Cloning: a Laboratory Manual, 3rd edn. Cold Spring Harbor, NY: Cold Spring Harbor Laboratory.

Sircili, M. P., Walters, M., Trabulsi, L. R. \& Sperandio, V. (2004). Modulation of enteropathogenic Escherichia coli virulence by quorum sensing. Infect Immun 72, 2329-2337.

Surette, M. G. \& Bassler, B. L. (1998). Quorum sensing in Escherichia coli and Salmonella typhimurium. Proc Natl Acad Sci U S A 95, 70467050.

Svenningsen, S. L., Waters, C. M. \& Bassler, B. L. (2008). A negative feedback loop involving small RNAs accelerates Vibrio cholerae's transition out of quorum-sensing mode. Genes Dev 22, 226-238.

Tanaka, T., Maeda, M., Kohno, H., Murakami, M., Kagami, S., Miyake, M. \& Wada, K. (2001). Inhibition of azoxymethane-induced colon carcinogenesis in male F344 rats by the citrus limonoids obacunone and limonin. Carcinogenesis 22, 193-198.

Tian, Q., Miller, E. G., Ahmad, H., Tang, L. \& Patil, B. S. (2001). Differential inhibition of human cancer cell proliferation by citrus limonoids. Nutr Cancer 40, 180-184.

Tu, K. C. \& Bassler, B. L. (2007). Multiple small RNAs act additively to integrate sensory information and control quorum sensing in Vibrio harveyi. Genes Dev 21, 221-233.

Vanamala, J., Leonardi, T., Patil, B. S., Taddeo, S. S., Murphy, M. E., Pike, L. M., Chapkin, R. S., Lupton, J. R. \& Turner, N. D. (2006). Suppression of colon carcinogenesis by bioactive compounds in grapefruit. Carcinogenesis 27, 1257-1265.

Vikram, A., Jayaprakasha, G. K. \& Patil, B. S. (2007). Simultaneous determination of citrus limonoid aglycones and glucosides by high performance liquid chromatography. Anal Chim Acta 590, 180186.

Vikram, A., Jayaprakasha, G. K., Jesudhasan, P. R., Pillai, S. D. \& Patil, B. S. (2010a). Suppression of bacterial cell-cell signalling, biofilm formation and type III secretion system by citrus flavonoids. J Appl Microbiol 109, 515-527. 
Vikram, A., Jesudhasan, P. R., Jayaprakasha, G. K., Pillai, S. D. \& Patil, B. S. (2010b). Grapefruit bioactive limonoids modulate E. coli O157: H7 TTSS and biofilm. Int J Food Microbiol 140, 109116.

Walters, M. \& Sperandio, V. (2006). Autoinducer 3 and epinephrine signaling in the kinetics of locus of enterocyte effacement gene expression in enterohemorrhagic Escherichia coli. Infect Immun 74, $5445-5455$
Wang, X., Yao, X., Zhu, Z., Tang, T., Dai, K., Sadovskaya, I., Flahaut, S. \& Jabbouri, S. (2009). Effect of berberine on Staphylococcus epidermidis biofilm formation. Int J Antimicrob Agents 34, 60-66.

Yu, J., Wang, L., Walzem, R. L., Miller, E. G., Pike, L. M. \& Patil, B. S. (2005). Antioxidant activity of citrus limonoids, flavonoids, and coumarins. J Agric Food Chem 53, 2009-2014.

Edited by: V. Sperandio 